\title{
DIFFICULTIES OF MANET FOR MOBILE SOCIAL NETWORKS
}

\author{
Mahesh Dandugudum, Nagendar Yamsani \\ Department of Computer Science and Engineering S R Engineering College \\ Warangal Urban, India \\ mahesh_d@srecwarangal.ac.in,nagendar.y@srecwarangal.ac.in
}

\begin{abstract}
In the last years mobile networking via sensible phones associated mobile telephones is wide accomplished as an infrastructure based mostly net- operating. The supplier grants a reasonable and stable access to the net, which might be employed by applications within the same approach because it is employed on stationary computers. However, several mobile devices support a spread of communication interfaces that are suit- ready for ad-hoc communication. As an example, local area network and Bluetooth are often used for ad-hoc networking. One reason, why these networking devices are seldom utilized in ad-hoc mode by mobile applications, is that limitations within the dependableness of network access ought to be thought-about as long as they need to supply over 1-to-1 communication. This contribution points out, that despite all technical problems the thought of social aspects and industrial aspects may be a major purpose for any success off MANET technology for mobile applications. We tend to discuss a message central approach to ad-hoc networking that depends on straightforward store and forward mechanism to unfold knowledge asynchronously within the network. This system is used for specific applications solely, that depends on tailored value-chain setups to be unfolded within the market. We tend to conjointly suggest the appliance specific constraints that go on in with the kidnapping of infrastructure-based networking.
\end{abstract}

Keywords: Mobile ad-hoc communication; MANET technology; tailored value-chain setups

\section{INTRODUCTION}

Nowadays smart phones are geared up with more than one communiqué interfaces, which provide a capacity interconnectedness for numerous programs, e.g. get right of entry to web primarily based social networks which include face book or Twitter or cellular community services which include Aka Aki. In maximum cases, the underlying networks rely on centralized infrastructures that are sure to stationary gadgets, consisting of get right of entry to factors, mobile phone radios. In recent years, mobile phone applications (offerings that may be downloaded from app markets which includes ITunes or Android market onto the mobile telephones) have increased the diffusion of cell networks and associated principles.

According to a current com Score Study conducted in 2010 access to Face book via mobile browser grew $112 \%$ in the past year, while Twitter experienced a 347\%-jump [1]. That means that about 25.1 million mobile users accessed Face book and 4.7 million users accessed Twitter via their mobile browser. More than $30 \%$ of Smartphone- owners access social networking sites via mobile browser. By comparison, just $6.8 \%$ of feature phone users accessed social networking sites on their mobile phones. These figures do not include access of the social networking services by the nearly 6 million mobile phone owners who do so exclusively through mobile applications [1].

Usually providers regulate the access to the Internet, the traffic control, and the maintenance of the applications. In contrast to this Mobile Ad Hoc Networks (MANETs) allow data exchange between mobile devices directly without the need for a centralized service unit. These services are enabled on transmission standards such as Bluetooth and follow store-and-forward principles. However, by the upcoming of mobile phone applications in the last years it seems that centralized services crowd out decentralized approaches in the market. Regarding this, we ask for current areas of application for MANETs as well as for parameters that barrier their diffusion.

\section{BACKGROUND}

Lugano [2] defined mobile communal software (MCS) so "a classification regarding mobile applications whose scope is to help convivial interaction among interconnected persons [...] exploiting the media convergence technique and the growing power concerning mobile units according to offer a variety of services."

Following Tasch and Bakel [3], mobile social software program can be understood as an infrastructure for mobile social internetworks (MSN), which are described as "businesses or peer-agencies in a town which can be specifically communicating via mobile services. Those mobile offerings enrich their communication and facilitate coordination of common activities". 
In that association the terms "Location Based Mobile Networking” yet "Pervasive Social Networking (PSN)" is fast back synonymously. Longevity they pencil the aggregate concerning pervasive computing or communal networks. This kind over soft- sensible permits customers according to find then hyperlink together with mean users, whosoever are stability durability permanency at a close by area then anybody close in imitation of other customers due to the fact on theirs convivial scheme [4, 5].

In standard MSS are characterized by detecting, considering, and adapt the current context of the individuals to functionalities of the software. Similarly context facts is e.g., temperature, geographic position, lightdepth, sound quantity, which can be detected via unique sensors of the hardware device. Currently there are a variety of services, which give attention to exploiting the geographic role to create no offerings (e.g. mashups). In recent years technical in addition to social and monetary elements of MANETs were item of numerous educational articles, e.g., [6], [7], [8], [9], [10]. Based totally on a framework of Hoffmann et al. [11] we can talk relevant factors of MANETs almost about current areas of software and obstacles of their diffusion.

Table 1: Framework on Media Access Control (MAC)

\begin{tabular}{|l|l|}
\hline Aspects & Characteristics \\
\hline Service and Scenarios & $\begin{array}{l}\text { Framing and environment, use cases, willingness to pay, degree of } \\
\text { innovation, customer requirements }\end{array}$ \\
\hline Service Network & Requirement profiles, business models, business case, networking structures \\
\hline Technologies & UMTS, DAB, speech synthesis, audio files, OSGi, platform \\
\hline Prototype and Platform & Architecture, implementation, general service platform \\
\hline Safety Aspects & Safety aspects, recommendations, legal aspects, potential for distraction \\
\hline Service Roll-Out & Service as seen by the customer, service provider roles etc. \\
\hline
\end{tabular}

III. ASPECTS OF MANETS

These attached factors over MANETs permanency notice to the utility permanency strata extra than after the underlying empirical realization. Technically MANETs do keep cooked using distinctive technologies. For our prototype implementation described last on we listen stability of an understanding permanency concerning MANETs as like multi-hop toughness networks among cell gadgets because advice manufacture which may additionally be time-shifted then as is unbounded in imitation of a centralized infrastructure.

\section{Service and Scenarios:}

The described concept of MANET-based message transfer may be used to run several packages consisting of an electronic bulletin board, community functions, and cell getting to know situations or to comprehend site visitor's notification services. Inside the following 3 examples of viable MANET usage are rapidly presented:

- Community Features - Combining who-is-online lists with position based information

Community offerings inclusive of configuring an individual profile using who-is-on-line lists or complicated reputation systems may be provided with the aid of mobile advert-hoc networks, e.g. for virtual groups Producing social network consequences may be used as one key element to boom diffusion of the defined popular. Taking part in a digital community with one's very own, selfadministrated, personalized person profile enables $\quad$ MANET packages to provide many services through sharing profile information through ad-hoc message propagation: e.g. to meet human beings with special pastimes or to be knowledgeable one of the who-is-on line listing is in the cutting-edge nearby area.

- Environment for Ubiquitous, Pervasive, Mobile E-Learning

To satisfy the necessities for ubiquitous e-getting to know a technical solution for the alternate of learning content can be discovered in advert hoc messaging [12]. Hence, MANETs are relevant to exchange messages and mastering objects among individuals. This system does not even require any person interaction, a connection can be established and data can be shared routinely.

- Mobile Bulletin Board - Category-based routing and anonymous messaging

A mobile bulletin board can be used to send messages addressed to all individuals in a specific area (non consistent with- personal messages). Defining distinctive classes, which you possibly can enroll in, can limit receiving posts from bulletin boards. for instance, an digital bulletin board can be used to signalize specific pursuits or offers to other human beings nearby. By means of helping a couple of node hops messages can be dispatched to a huge range of individuals. Limiting the wide variety of legitimate hops may be used as a device to manipulate the variety of the neighborhood location, wherein this message can be obtained. 


\section{SERVICE NETWORK}

Turnover of portable information administrations (without instant messages or MMS) will ascend from $€ 1.6$ billion in 2007 to $€ 5.7$ billion in 2012 in Germany [13]. In 2007 27\% of the Germans who utilize cutting edge cell phones as of now have gone by landing pages by means of cell phones (information by Mobile Web Watch). In view of a hypothetical system of Chesbrough and Rosenbloom [14] we depict pertinent viewpoints for planning a plan of action, which administrations depend on a MANET approach.

\section{- $\quad$ Value proposition}

MANET is another and creative innovation for information exchange between cell phones accessible to suppliers of virtual groups. In this manner, the scope of administrations for their own particular clients (group individuals) increments. Moreover, there is plausibility for group suppliers to put target-aggregate situated publicizing inside the portable group. New potential outcomes of profile trade and classification based news trade, which might be utilized for sending and getting business promotions and also purchase and offer request, are offered to clients. By using the innovation, online contacts from individuals from online systems can be exchanged to reality. The client can contact people from his virtual system up close and personal. Additionally benefits emerge to the way that the market for exchange and trade organizations, easygoing work and things, for example, furniture, writing, and so on can be changed from stationary elements (e.g. PCs, release sheets) to where group individuals meet, in actuality. The all inclusive character of the announcement load up empowers MANET to offer further utility-making additional items over the span of time. Cases for this are: internet dating, learning bunches in colleges, and arrangements for occasions in urban communities. Applications, which are normally limited to the Internet (e.g. group applications), can be utilized transportable.

\section{- $\quad$ Market segment and competitive strategy}

The basic versatile plan of action concentrates on suppliers of enormous Internet people group as the client gathering. New and imaginative highlights in light of MANET innovation can be added to group supplier's administration portfolio. In this way, online groups can advance to portable groups, causing prompt surplus incentive for its individuals. The recognized ideas, for example, Nokia sensor or GyPsii, take after comparable methodologies as MA-NET. A natty gritty examination uncovered that these task couldn't get a minimum amount of clients. In this way, full benefits were not understood. The investigation additionally shows an expanding enthusiasm of virtual groups towards the help of versatile administrations. This photo is substantiated by ventures that in this setting have been started by group administrators. Otherwise known as Aki, for instance, is an Internet benefit that empowers clients to show the individual profile inside the group on the cell phone. The profile is put away in an online database, Aka-Aki members can be recognized through the Bluetooth sensor of a mobile phone and client profiles can be downloaded from the Internet. A fruitful dispersion of MANET innovation is influenced by a few variables, for example, the supply of the populace with Bluetooth cell phones, improvements in the utilized working frameworks and vitality re-wellsprings of mobile phones.

\section{- $\quad$ Value chain structure}

The plan of action bases on appropriating programming, which empowers the utilization of MANET innovation by means of cell phones. The product is adjusted to the necessities of gatherings and situations, in which it is utilized. Cases for that are:

- $\quad$ Supplement of administrations of virtual groups, for example, Facebook or huge discourse gatherings by MANET innovation. Client profiles can be traded on the web and by coordinate transmission between mobile phones.

- $\quad$ Trade of news between clients of cell phones, which incorporate position-subordinate components (e.g. contacts for basic neighborhood occasions, for example, shows, fairs, employment and level chasing, purchasing and offering of vigorously trans-versatile products).

- $\quad$ Trade of utilizations and data, for instance in setting of e-learning situations. Information ex-change and dialogs can happen suddenly and area autonomous.

Transferability of online contacts from systems to genuine is critical keeping in mind the end goal to become acquainted with individuals and to talk about up close and personal. The innovation demonstrates if a man from a system ends up in close region (as a result of a multi-bounce methodology a scope of more than 100 meters can be accomplished), and contacts are empowered.

- Information trade is free for clients, in light of the fact that no volume-depending exchange costs cause (tantamount to a standard web get to).

- Utilize does not require new gadgets, but rather depends on equipment, which is far reaching. Programming download is intentionally and with no expenses.

- The program can be downloaded from the Internet or straightforwardly shared among mobile phones. 
- Clients can subjectively actuate and deactivate MANET application on their mobile phone.

- Revenue generation and position in value network

The income display tends to group suppliers as immediate purchasers and permit takers (programming licenses and administrations). The plan of action incorporates two items:

(1) A MANET programming empowers expansion of functionalities of a PDA.

(2) Providers of online groups may buy client rights as licenses. Second, the administrations might be offered in the setting to this product. Cases for this are adaption as per clients' needs, bolster administrations, programming of extra interfaces and functionalities and interview administrations for innovation presentation.

\section{TECHNOLOGIES}

As per run of the mill layer models, as known from the ISO-OSI layering, the engineering has been planned with a programmable Bluetooth interface, alongside a message storehouse as information stockpiling. The contrasts between the layer display bases on the ISO-OSI standards and the model usage can be found in how the applications accesses the information: It is of awesome application's enthusiasm to decide the degree (in space and time) of a message. Configurable message channels control the entrance of uses towards the store content. Message properties, set by the different applications by methods for message channels, consider certain message trade manages between the mobile phones. Aside from that, the applications have guide association with the message trade genius cases itself.

\section{PROTOTYPE AND PLATFORM}

A proper model for MANETs may base on messages as a general structure. Messages are transmitted between MANET hubs. The message header ("General Header") is trailed by application-particular fields ("Application Header"), lastly by the application-particular message payload itself. The diverse parts of a message are dealt with by various segments of the MANET design. The message store investigations the general header, the assessment of the application header happens in the application particular channel associated with the vault and the message information are gone through to the application.

Recently got messages are added to the message store. Rejected messages are disregarded from assist master messaging inside the real part. That implies that messages dismissed by the application particular channel are not passed on to the application but rather still exist in the message store. Accordingly, in multi-bounce situations such messages still will be passed on to different hubs in extend notwithstanding when they are not important to the hubs possess applications. This is a piece of the MANET store-and-forward idea. Hubs store messages for a most extreme measure of time and convey them to short proximity hubs, with capacity time and greatest jump consider restricting elements. That avoids messages to live perpetually inside the system and clog can be lessened. Messages can be recognized by sender address, message payload message validation code, and jump check, among others. This builds up a multicast-like system so as to synchronize message storehouses of hubs inside a specific separation.

Storehouse association and message putting away are key regions inside the MANET idea. Since the fundamental stage imagined for MANET comprises of cell phones and other little computerized gadgets with impressively constrained capacity and calculation abilities, the vault taking care of must be deliberately composed, alongside message reserving and proficient capacity systems. Comparing to existing methodologies for information administration in unequivocally asset restricted frameworks, a sifting framework has been executed, which can likewise be utilized and reached out by applications for different message-separating purposes $[10,15]$.

\section{SECURITY ASPECTS}

Frameworks that offer information in an obscure system condition must address top to bottom security issues, which are known from a scope of normal Internet applications. This incorporates approval, verification, put stock in information transmission and different issues that are expected to ensure secure exchanges in individual informing successions. Another idea to actualize security works in a circulated portable system is the web-of-confide in approach. Web of trust is a prevalent point of ebb and flow inquire about and permits security benefits in circulated organize conditions without unified online trust specialists that execute those obligations and duties in like manner arrange set-tings [16, 17]. As Pirzada and McDonald [18] depict, contingent upon a focal trust specialist is an illogical requirement for portable impromptu systems. They show a model for trust-based correspondence in specially appointed systems that additionally exhibit that a focal trust expert is a pointless prerequisite.

A web-of-trust model can deal with various sorts of hubs that demonstration not of course. Lacking hubs must be by-passed, vindictive hubs must be detached while cautioning different hubs adjacent and narrow minded hubs must be constrained in their activities. Therefore a capable model needs to cover a scope of hubs rowdiness and think about their immediate effect on security viewpoints. Since security issues are not the principle center in the field of MANET investigate now, there is no verification of idea execution yet. This is a piece of further advancement and must be incorporated when the MANET idea is utilized as a part of uses and items. 


\section{CONCLUSION}

Our examination in the field of MANET prescribes that accommodating message correspondence can be displayed for an off the cuff framework that serves numerous particular applications. These applications ought to be expected to rely upon asynchronous message passing, indicated time-moved message inciting. MANETs allow a speedy dispersal of messages in thick frameworks inside a given number of hops.

As we brought up the accomplishment for MANET advancements not just rely upon specialized issues for which arrangements can be given while focusing on every perspective independently. The principle point why we scarcely observe any use of genuine MA-NET usage is that the many-sided quality of such systems must be taken care of when the applications never again need to depend on a steady and synchronous system association. Another point is that multi-bounce time-moved message exchange needs applications to go about as social centers that additionally pass on data that isn't of enthusiasm for the applications own particular purposes. As appeared, a few parts of the esteem chain structure of portable interpersonal organizations don't consider these perspectives and accordingly are planned utilizing basic progressive foundation systems. Inside the extent of further research new MANET more models will be created. This work must be united with discoveries of other applicable inquired about in versatile situations as for social conduct and esteem chain advancement.

\section{REFERENCES}

[1] ComScore, Study on social networking access via mobile browser, Reston, VA (2010).

[2] Lugano, G., Mobile social networking in theory and practice, First Monday, Volume 13, Number 11 (2008).

[3] Tasch, H., Bakel, T., Location Based Community Services for a new Type of Web Communities, IADIS International Conference Web Based Communities, Lisbon (2004).

[4] Mokhtar, S., Licia Capra, L., A Middleware Service for Pervasive Social Networking, Proceedings of the international Workshop on Middleware For Pervasive Mobile and Embedded Computing, USA (2009).

[5] Mokhtar, S., Licia Capra, L., From pervasive to social computing: algorithms and deployments, Proceedings of the International Conference on Pervasive Services, London, UK (2009).

[6] Beckman, P., S. Verma, J. Mindel, Innovating with Technology: The Impact of Overload, Autonomy, and Work and Family Conflict, Journal of Information Technology Theory and Application (JITTA), 9:4 (2009) 67-81.

[7] Chin, K.-W., Judge, J., Williams, A., \& Kermode, R., Implementation experience with MANET routing protocols. SIGCOMM Comput. Commun. Rev, 32(5) (2002) 49-59.

[8] Royer, E.M., \& Toh, C.-K., A Review of Current Routing Protocols for Ad Hoc Mobile Wireless Networks. IEEE Personal Communications (1999).

[9] Xu, K., Hong, X., \& Gerla, M., Landmark routing in ad hoc networks with mobile backbones. J. Parallel Distributed Compututing., 63(2), (2003) 110-122.

[10] Ni, S.-Y., Tseng, Y.-C., Chen, Y.-S., \& Sheu, J.-P., The broadcast storm problem in a mobile ad hoc network. Proceedings of the 5th annual ACM/IEEE international conference on Mobile computing and networking, ACM Press, Seattle, Washington, USA, (1999) 151-162.

[11] Hoffmann, H; Leimeister, Jan Marco; and Krcmar, Helmut, A Framework for Developing Personalizable Mobile Services in Automobiles. Proceedings of the ECIS 2007. Paper 187.

[12] Ogata, H., Yano, Y., Supporting Knowledge Awareness for Ubiquitous CSCL. E-Learning, (2000) 2362-2369.

[13] Bitkom, Mobile Life 2012, http://www.bitkom.org/de/presse/56204_54145.aspx (2008).

[14] Chesbrough, H., Rosenblom, R., The Role of the Business Model in Capturing Value from Innovation, Harvard Business School Press, Boston (2002) 529-556.

[15] Pei, G., Gerla, M., Chen, T.-W., Fisheye state routing: a routing scheme for ad hoc wireless networks. Proceedings of the IEEE International Conference on Communications, (2000) 70-74.

[16] Balfanz, D., Smetters, D.K., Stewart, P., \& Wong, H.C., Talking to strangers: authentication in ad-hoc wireless networks. Proceedings of the Network and Distributed System Security Symposium (2002).

[17] Michiardi, P., \& Molva, R., CORE: A Collaborative Reputation Mechanism to enforce node cooperation in Mobile Ad hoc Networks, IFIP Conference Proceedings, Vol. 228, (2001) 107-121.

[18] Pirzada, A. A., McDonald, C., Establishing trust in pure ad-hoc networks. Proceedings of the 27th conference on Australian computer science, (2004) 26.

\section{AUTHORS PROFILE}

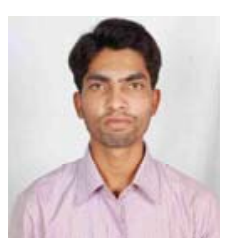

Mahesh Dandugudum received Master's degree in Computer Science and Engineering in 2015 from Jawaharlal Nehru Technological University, Hyderabad, India. . He worked as Assistant Professor in the Department of Computer Science and Engineering in SAHAJA Institute of Technology for Women (SITW), Karimnagar for 1 year. Presently he is working as Assistant Professor in the Department of Computer Science and Engineering, S R Engineering College (Autonomous), Warangal, Telangana, from January, 2017 to till date. His research areas include MANET Networks, Networks Security and IoT. 


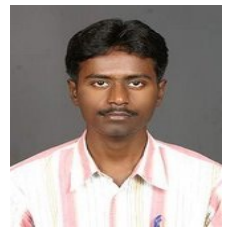

Nagendar Yamsani received Master's degree in Computer Science and Engineering in 2009 from Jawaharlal Nehru Technological University, Hyderabad, India. He has 8 years of teaching experience. Currently he is working Assistant Professor in the Department of Computer Science and Engineering in S R Engineering College (Autonomous), Telangana, India and Coordinator, S R R \& D Centre. He has published Thirteen International Journals and Three International Conference Papers. His research areas include Networks Security, Automata and Data Mining. 